\title{
Sostenibilidad y ecoeficiencia en arquitectura
}

\author{
Ángeles Maqueira Yamasaki \\ Universidad de Lima \\ Ingeniería Industrial n² 29, 2011, ISSN 1025-9929, pp. 125-152 \\ Recibido: 23 de febrero del 2011 / Aprobado: 9 de mayo del 2011
}

\begin{abstract}
Resumen: El artículo es una aproximación al tema de la sostenibilidad desde el punto de vista de la arquitectura. Concebida como el encuentro entre la vida y el espacio, la arquitectura es una de las disciplinas del ser humano desde la cual podemos cuestionar los criterios con que se diseñan los objetos que utilizamos en nuestra vida diaria, para proponer nuevas alternativas que contribuyan al cuidado del medioambiente. Repasando las tecnologías de las que disponemos actualmente para aproximarnos a la sostenibilidad, se presenta una idea específica de proyecto que sirve de pretexto para hacer arquitectura sostenible.
\end{abstract}

Palabras clave: arquitectura sostenible / sostenibilidad / ecoeficiencia / protección ambiental / proyectos de arquitectura / Perú

\section{Sustainability and eco-efficiency in architecture}

ABSTRACT: This article is an approximation to the big topic of sustainability, from the architect's point of view. Architecture, where life and space converge, is one of the human disciplines where one can question the criteria by which the objects that we use in our daily lives are designed, so one can propose new alternatives that contribute to environmental care. Reviewing the technologies developed until now to achieve sustainability, a specific architecture project is presented, just as an excuse to do sustainable architecture.

Keywords: sustainable architecture / sustainability / eco-efficiency / environmental protection / architectural projects / Peru 


\section{SOSTENIBILIDAD}

Veinticuatro años después de que la Comisión de Medio Ambiente y Desarrollo de Naciones Unidas consolidó el concepto de desarrollo sostenible, aún existen discrepancias — un tanto filosóficas - con respecto a qué es la sostenibilidad y cómo debemos entender el desarrollo sostenible. Este último concepto encierra dos términos que se yuxtaponen: el desarrollo implica un cambio constante para mejorar una realidad y la sostenibilidad un equilibrio; el desarrollo y el equilibrio son conceptos intrínsecamente opuestos. Por ello se dice que el concepto de desarrollo sostenible puede parecer utópico, en el sentido de que una utopía es considerada como un horizonte inalcanzable, pero que en la medida que caminemos hacia él, avanzamos. Debemos, entonces, mirar el término como una meta, conscientes de que el desarrollo sostenible per se no llegará, caminar hacia él de alguna manera aliviará a nuestro planeta del peso que le hemos obligado a cargar.

$\mathrm{Al}$ margen de las discrepancias con respecto a lo anterior y a aquellas que generan la traducción del término del inglés sustainability al español 'sostenible' o 'sustentable', tenemos una primera definición internacionalmente reconocida que se encuentra en el Informe Brundtland (1987), fruto de los trabajos de la Comisión de Medio Ambiente y Desarrollo de Naciones Unidas y que además figura en la Declaración de Río de Janeiro (1992): "Aquel desarrollo que satisface las necesidades de las generaciones presentes sin comprometer las posibilidades de las generaciones futuras para atender sus propias necesidades".

En este marco, los tres pilares o aspectos fundamentales de la sostenibilidad son:

- Ambiental.- Consiste en la preservación de los ecosistemas locales y globales, equilibrando la balanza de todo aquello que extraemos y aquello que le devolvemos al ecosistema.

- Social.- Consiste en mejorar el bienestar general de una comunidad, dando las mismas oportunidades a todos sus habitantes, garantizando su crecimiento personal, educación, salud y trabajo.

- Económico.- Significa que un desarrollo es rentable cuando crea riqueza para los inversionistas y trabajo para las personas de la comunidad, sin amenazar el futuro sustento de energía y agua gracias a la implementación de políticas estratégicas. 
El desarrollo sostenible busca en cierta forma la armonía global. Es una meta que apela a la razón y a la ética, ya que implica un beneficio tanto material como espiritual de las personas. De alguna manera, su objetivo es que seamos seres integrales, completos y con las mismas oportunidades.

\section{LA ARQUITECTURA DENTRO DEL MARCO DE LA SOSTENIBILIDAD}

Hacer de la arquitectura un proyecto sostenible ya no es una necesidad sino una urgencia. Ponerle la etiqueta de "sostenible" a un proyecto arquitectónico es algo que no debe tomarse a la ligera. Al respecto, Edwards (2008) sostiene:

[...] para el arquitecto, la sostenibilidad es un concepto complejo. Gran parte del proyecto sostenible tiene que ver con la reducción del calentamiento global mediante el ahorro energético y el uso de técnicas - como el análisis del ciclo de la vida - con el objetivo de mantener el equilibrio entre capital inicial invertido y el valor de los activos fijos a largo plazo. Sin embargo proyectar de forma sostenible también significa crear espacios saludables, viables económicamente y sensibles a las necesidades sociales. Supone respetar los sistemas naturales y aprender de los procesos ecológicos.

Debido a que el rubro constructivo consume más del cincuenta por ciento de nuestros recursos, proyectar de manera sostenible significa equilibrar las materias primas (materiales y energía) con los residuos. Se trata de lograr que el ciclo sea un círculo cerrado; de reutilizar y reciclar los residuos, sacar provecho de ellos y regenerar la materia prima con la actividad misma que se da dentro de los espacios. 


\section{Cuadro 1}

Comparativo del consumo de la construcción con relación al resto de actividades

\begin{tabular}{ll} 
Materiales & $\begin{array}{l}\text { El } 60 \% \text { de todos los recursos mundiales se destinan a la } \\
\text { construcción (carreteras, edificios, etcétera). }\end{array}$ \\
\hline Energía & $\begin{array}{l}\text { Aproximadamente el } 50 \% \text { de la energía generada se utiliza } \\
\text { para calentar, iluminar y ventilar edificios, y un } 3 \% \text { adicional } \\
\text { para construirlos. }\end{array}$ \\
\hline Agua & $\begin{array}{l}\text { El } 50 \% \text { del agua utilizada en el mundo se destina a abastecer } \\
\text { las instalaciones sanitarias y otros usos en los edificios. }\end{array}$ \\
\hline Tierra & El $80 \%$ de la mejor tierra cultivable que deja de utilizarse para \\
la agricultura se utiliza para la construcción.
\end{tabular}

Fuente: Edwards (2008).

Para poder proyectar considerando las posibilidades de reciclaje y reutilización de estas materias primas se debe conocer la vida útil de los diferentes elementos que componen la arquitectura, ya que no se estará diseñando únicamente para el presente o para un futuro indefinido, sino para el lapso de tiempo exacto en que cada uno de estos elementos será útil. De esta manera, se deben elegir los materiales más eficientes —en cuanto a la posibilidad de ser reciclados o reutilizados- en relación con su vida útil.

\section{ECOEFICIENCIA}

En la cultura de la sostenibilidad nace un término un poco más tangible: la ecoeficiencia. Como se menciona en el punto 1, el concepto de desarrollo sostenible entra en el campo de lo utópico, que visto como una meta será siempre beneficioso. Por ello se tiende a recurrir a un concepto más concreto y medible, como lo es la ecoeficiencia:

La ecoeficiencia es una cultura administrativa que guía al empresariado a asumir su responsabilidad con la sociedad, y lo motiva para que su negocio sea más competitivo, adaptando y readecuando los sistemas 
productivos existentes a las necesidades del mercado y del ambiente, y de esa forma consolidar niveles más altos de desarrollo económico, social y ambiental (Vitaliz 2010).

La visión central de la ecoeficiencia se puede resumir en la expresión "producir más con menos". Estamos hablando no solo del uso de materias primas, sino también de materiales reutilizados o reciclados y de aquellos productos que resultan del procesamiento de residuos para reinsertarlos en los ciclos de un proyecto arquitectónico.

En la concepción de un proyecto arquitectónico ecoeficiente debemos traducir ese "más" en eficiencia energética y matérica, y ese "menos" en reciclabilidad y reutilización de los materiales seleccionados, tratamiento de residuos y reducción de emisiones contaminantes al entorno. Se trata de hallar el equilibrio entre los recursos y los residuos y crear un sistema lo más cerrado posible, imitando los ciclos naturales, donde los residuos sean transformados en materias primas.

\section{ECOTECNIAS DEL PASADO PERUANO}

La tecnología constructiva utilizada en el pasado en cualquier territorio suele darnos pautas para enfrentarnos tanto al clima como a la geografía del lugar. Por ello, es necesario, antes de proponer un proyecto ecoeficiente, repasar dicha tecnología, para proponer sistemas y materiales coherentes con la realidad en la que se inserta la arquitectura.

\subsection{Construir con tierra: El adobe}

$\mathrm{El}$ adobe es un ladrillo formado por una masa de arcilla y algún aditivo, secada al sol y al aire; se caracteriza por ser un material que se emplea sin cocción previa. Es un antiquísimo sistema de construcción que se encuentra en muchas regiones del mundo. Funciona muy bien en zonas de clima seco.

Se fabrica con tierra arcillosa y agua, mediante un molde, y se deja secar al sol. Para evitar que se agriete al secar se añaden a la masa paja, crines de caballo o heno seco, que sirven como armadura. Las dimensiones adecuadas deben ser tales que el albañil pueda manejarlo con una sola mano. 
Tiene una gran inercia térmica, por lo que sirve de volante regulador de la temperatura interna; en tiempo de calor es fresco y tibio durante el invierno.

Debido a que puede deshacerse con la lluvia, requiere un mantenimiento sostenido, que suele realizarse con capas de barro. No es correcto hacerlo con mortero de cemento, puesto que la capa resultante es poco permeable al vapor de agua y conserva la humedad interior, por lo que el adobe se desharía desde dentro.

Su uso se inició durante el periodo formativo (2000 a. C. - 200 a. C.) en las huacas o templos de las civilizaciones costeñas (foto 1).

\section{Foto 1}

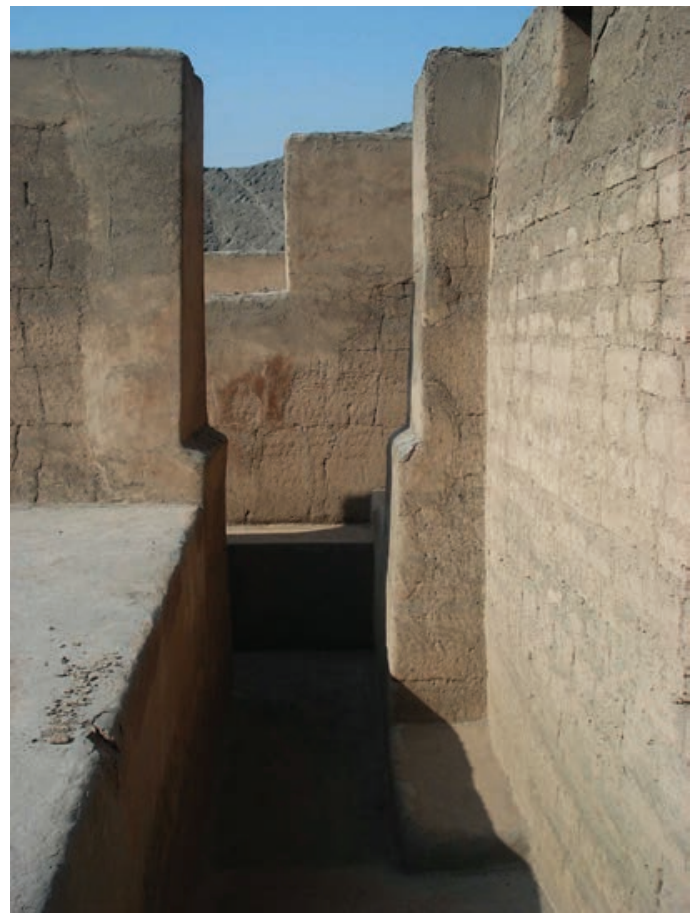

Puruchuco, Ate-Vitarte. 1440-1532.

Foto de la autora. 
En el Perú esta técnica se desarrolló tanto en la costa, sobre todo la costa norte, como en la sierra. Es evidente que su uso se debe primero a la presencia de la materia prima y a que la masa de sus anchos muros brinda estabilidad en los espacios interiores. Además, encontramos adobe en muchos otros lugares del mundo, desde Palestina y España hasta el sudoeste de Estados Unidos. Sin embargo, en el Perú adquiere una particularidad: el producto.

El resultado del uso del adobe en el Perú tiene que ver con la concepción metafísica del antiguo peruano: extraer de la tierra (pachamama) para adorar a la tierra. Las huacas son edificaciones características de las culturas preincaicas costeñas. Su forma emula al $a p u$, divinidad que no solo perteneció al panteón incaico sino también a las diversas culturas preincaicas de nuestro territorio. De esta manera, el material vernacular, propio de una zona, genera la arquitectura vernacular, propia del lugar, que a la vez nos habla de quién la construye y dónde.

A diferencia de la modernidad, los antiguos peruanos desarrollaban arquitecturas propias y adecuadas para cada ecosistema. Por ejemplo, la costa es una zona en su mayor parte árida, en la que construir con tierra no es sino la respuesta evidente.

\subsection{La caña y la quincha}

El uso de la caña en la arquitectura se inició en el periodo arcaico (5000 a. C. - 2000 a. C.) en la costa. Luego se adaptaría para la construcción de coberturas sobre las huacas de adobe o de piedra en las diversas regiones donde estas tecnologías fueron aplicadas, como estructura o como cerramiento, combinada con madera y tierra (quincha). Su utilización se extendería hasta nuestros días, primero como material complementario en la arquitectura vernacular y en los últimos años en la construcción de habitaciones en las playas y balnearios exclusivos (fotos 2 y 3 ).

La quincha, palabra quechua que significa cerco de palos o juncos, es una forma particular de utilizar la caña. Fue a partir de la época de la Colonia que se extendió aún más el uso de este sistema, al ser adoptado en gran medida por las clases dominantes. Después del terremoto producido en Lima en 1687 se promovió el uso de la quincha en sustitución de los pesados muros de adobe, hasta que los terremotos 
Foto 2

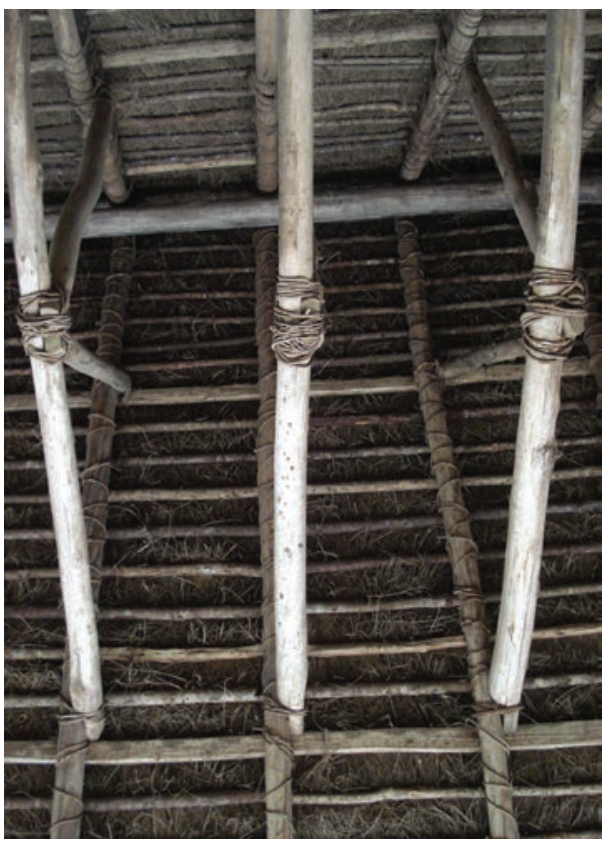

Techado construido con técnicas incas.

Foto de la autora.

\section{Foto 3}

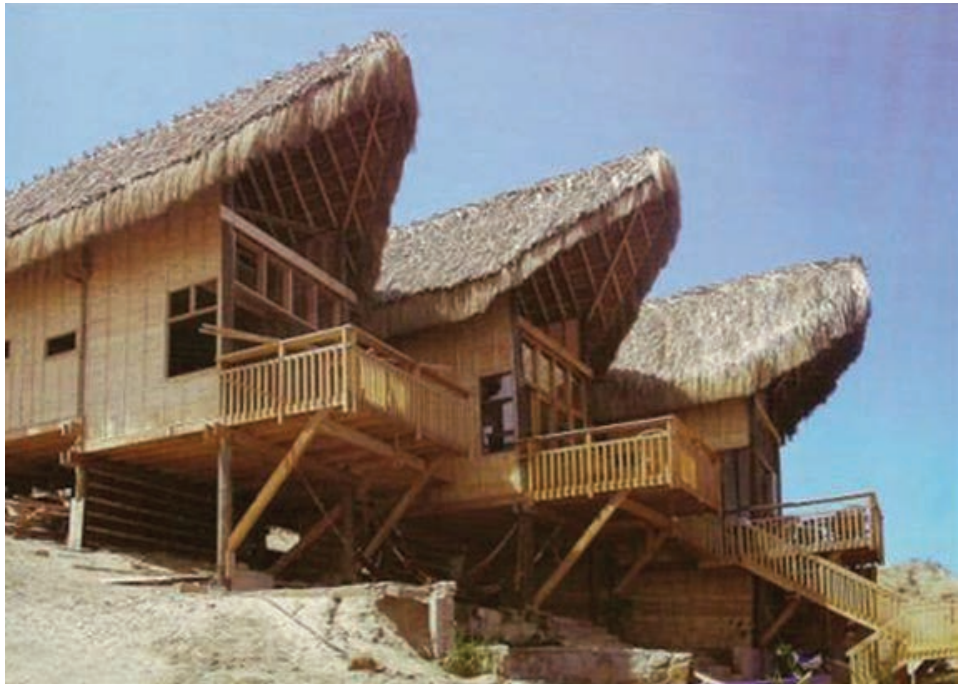

Bungalós Mancoral, Trujillo.

Arquitecto José del Carpio, 2006.

Fuente: Colegio de Arquitectos del Perú (2009). 
posteriores de 1940, 1966 y 1970 determinaron el empleo del ladrillo y del concreto armado; el resultado fue un espacio con ventajas térmicas constructivas y estructurales, debido a la flexibilidad del material, que hace no que resistan, como mal se dice, sino que "bailen" con el sismo, lo que evita el colapso de la edificación.

Entre las ventajas del uso de la quincha se pueden señalar las siguientes: el entramado de caña absorbe la energía, la madera tiene propiedades de flexibilidad y resistencia a la tracción y el barro provee fricción y masa para absorber el movimiento. Del mismo modo, el poco peso implica que se pueden alcanzar grandes alturas. Es evidente que es un sistema desarrollado por pobladores de una zona sísmica.

Por otro lado, el uso de la tierra como relleno y revestimiento es un sistema que protege de las inclemencias del clima, como el frío o el calor extremos. La tierra es un material poroso que respira y regula la humedad.

Además de la quincha como sistema, la caña como materia prima para la construcción de techos y estructuras diversas — de la misma forma en que se utilizó en la etapa precolombina de nuestra historiaproporciona una verdadera opción arquitectónica.

El bambú, llamado marona o taca en el Perú, es considerado el acero vegetal; es una fibra de una resistencia muy alta a la tracción y compresión; pertenece a la misma familia de la caña brava y la caña en general, por lo que nos brinda opciones de estructuración de techados y cerramientos mucho más pertinentes a las zonas cercanas al trópico, como la costa norte.

Las ventajas de los carrizos como alternativa para una cobertura son su ligereza y su pertinencia al lugar. Crea sombras frescas en lugares cálidos, por lo tanto, contribuye a la arquitectura bioclimática, además de ser rentable por tener un corto ciclo de crecimiento.

Asimismo, el bambú actúa como agente protector de los suelos y del agua. Su sistema radicular entretejido y la presencia de abundantes rizomas forman una intrincada red que amarra fuertemente las partículas de suelo, evitando la erosión, sobre todo en las laderas. Como reguladora de la calidad y cantidad del agua, el bambú ejerce control sobre los sedimentos y forma muros que evitan la pérdida de los caudales de los ríos. Además, la cantidad de oxígeno que produce un bambú es muy superior a cualquier otro sistema forestal sobre la misma superficie de 
terreno. Una hectárea de bambú captura cuarenta veces más CO2 que la misma superficie de pinos en un año.

Este material es muy utilizado en la arquitectura costeña contemporánea, especialmente en los balnearios, ya sea en casas unifamiliares o en hospedajes de pequeña y gran envergadura.

\subsection{Tecnología lítica}

En nuestro territorio, la piedra se utilizó desde el inicio mismo de la arquitectura; es decir, desde que los nómadas primitivos empezaron a construir pequeños espacios de protección (12.000 años a. C., periodos Lítico y Arcaico).

La piedra fue utilizada sobre todo en las regiones andinas, donde se encontraba en abundancia y se extraía de las canteras. Pero fueron los incas (siglos XIII-XVI) quienes llevaron la tecnología lítica a su máximo desarrollo (fotos 4 y 5 ).

Los incas dominaron de tal manera la tecnología lítica, llegando a elaborar distintos tipos de aparejo, asentado, juntas y perfiles de los muros, que respondían a los distintos tamaños y formas de los recursos que encontraban en sus canteras. Tuvieron que crear sistemas eficientes para el traslado y movilización de los bloques, que eran de considerable volumen y peso, que en algunos casos llegaban hasta los ocho metros y medio de alto.

A diferencia de la costa peruana, los Andes son una zona muy difícil para asentarse, por sus características geográficas y climáticas; sin embargo, los incas supieron aprovechar — con mucho ingenio y sobre todo respeto por su entorno- los recursos que las montañas les ofrecían.

Así, para el clima agresivo de la sierra qué mejor material que la piedra, maciza, voluminosa y con gran inercia térmica. Las habitaciones eran construidas con muros portantes de gaviones de canto rodado, con una estructura externa metálica.

Toda la tecnología lítica desarrollada respondía a lo que la naturaleza les brindaba, de tal forma que no tuvieron que introducir elementos extraños en sus ecosistemas para construir sus edificaciones. 
Foto 4

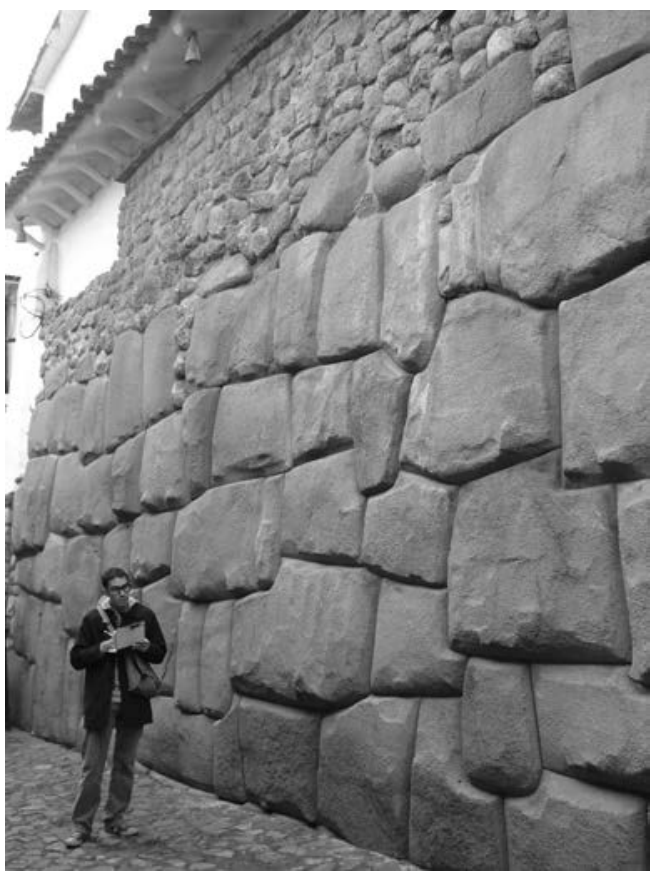

El uso de ecotécnicas locales es una manera de contribuir a la ecoeficiencia en arquitectura.

Foto de la autora.
Foto 5

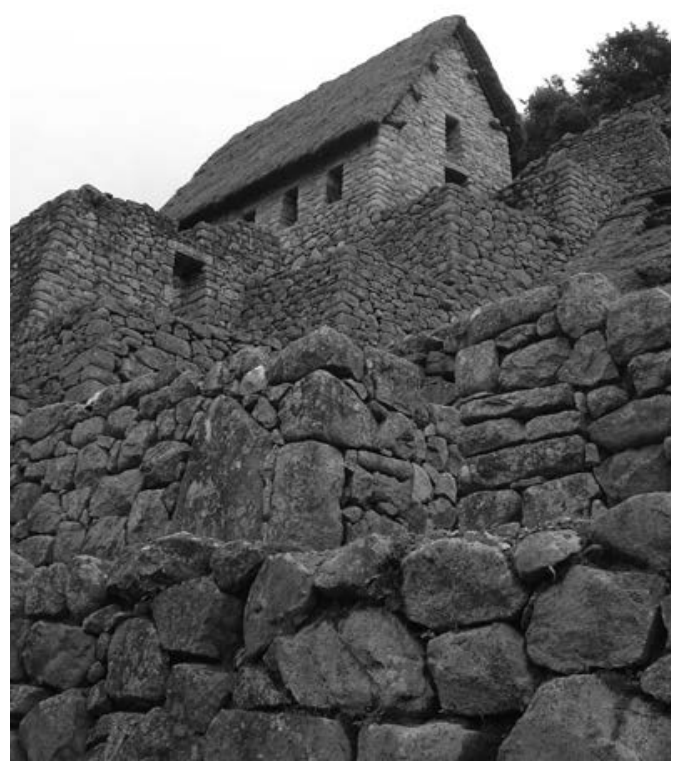

Macchu Picchu, Perú.

Foto de la autora.

\section{UN REFUGIO ECOEFICIENTE EN CHACLACAYO}

En el presente artículo se describe el desarrollo de un proyecto denominado El Refugio, el cual consiste en un alojamiento ecoeficiente para turismo solidario en el distrito limeño de Chaclacayo, ubicado a veintisiete kilómetros al este de la ciudad.

El mencionado distrito tiene un gran potencial turístico y es un lugar que permite diseñar un proyecto que contempla el uso de sistemas ecoeficientes, por el clima amable que presenta: una temperatura media entre $23,5^{\circ} \mathrm{C}$ y $16^{\circ} \mathrm{C}$, casi seis horas de sol diarias, baja humedad, ligeras precipitaciones $\mathrm{y}$ vientos.

El terreno está ubicado en la avenida San José N. ${ }^{\circ} 400$, en la urbanización Santa Inés; al pie de las estribaciones andinas que rodean la ciudad. Consta de $28.864,87 \mathrm{~m}^{2}$, con un área construida de $5.863,21 \mathrm{~m}^{2}$ y un área libre de $23.001,66 \mathrm{~m}^{2}$ (gráfico 1). 


\section{Gráfico 1}

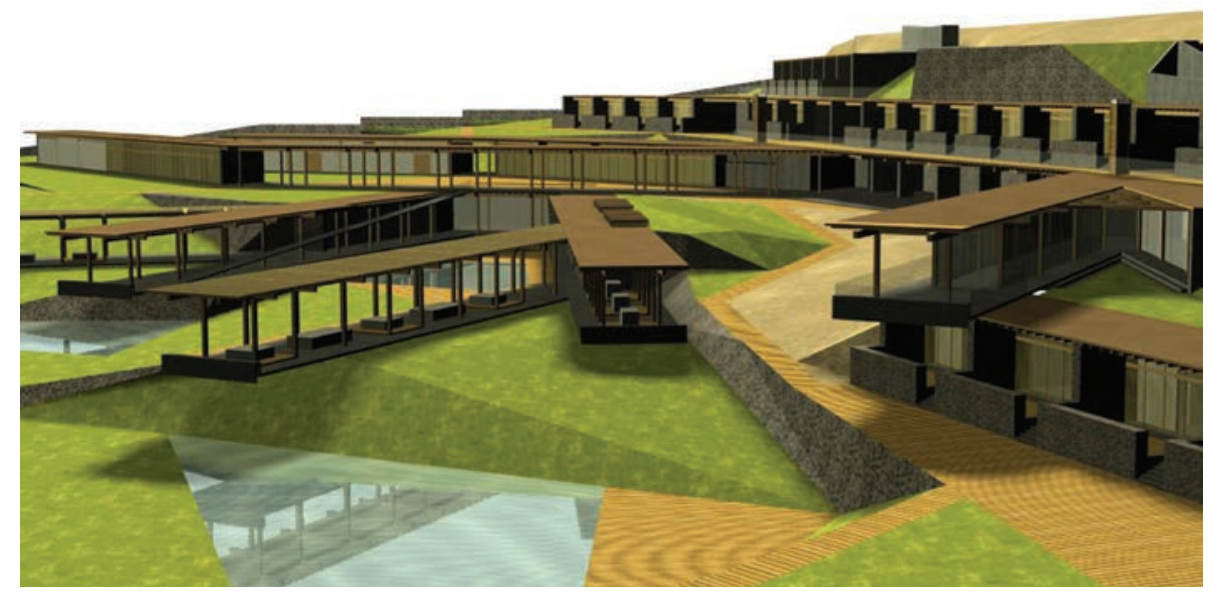

Vista panorámica del proyecto El Refugio.

Elaboración propia.

El diseño del proyecto tiene en cuenta el concepto de que para hacer arquitectura debemos pensar que, de alguna manera, estamos contribuyendo a la creación de la geometría de nuestro planeta. Al respecto, Perec dice:

[...] la concreción del mundo: algo más claro, más próximo a nosotros: el mundo, no ya como un recorrido que hay que volver a hacer sin parar, no como una carrera sin fin, un desafío que siempre hay que aceptar, no como el único pretexto de una acumulación desesperante, ni como ilusión de conquista, sino como recuperación de un sentido, percepción de una escritura terrestre, de una geografía de la que habíamos olvidado que somos autores (2002: 41).

La idea de simbiosis enmarca la concepción inicial del proyecto, que tiene un carácter social y solidario. La relación entre el albergue y el alojamiento es también simbiótica, al concebir el refugio como un albergue para el turismo solidario, en el que los huéspedes (consumidores), escogen este en lugar de otros centros recreativos, porque brinda la posibilidad de colaborar con la manutención de los niños albergados en él.

La intención del proyecto es aprovechar todo material disponible para cerrar ciclos. Estos materiales en general serán los residuos ge- 
nerados por el uso del espacio. Estos residuos son la basura (orgánica e inorgánica) y las aguas residuales (grises y negras). Por lo tanto, uno de los objetivos del diseño será volver a insertar estos residuos en el ciclo de vida del edificio.

El proyecto sostenible o ecoeficiente se apoya en el uso de energías renovables, buscando las más apropiadas para el lugar, el clima y el tipo de proyecto.

El diseño del refugio busca aprovechar la gran cantidad de horas de sol del lugar. Se proponen tres bloques de paneles fotovoltaicos en la parte superior; ya que a diferencia del terreno, que cuenta con una densa vegetación en los niveles inferiores, esta parte está conformada por un cerro árido y rocoso. La idea es "sembrar" energía en estos pequeños "bosques" de energía solar, la cual será almacenada y distribuida hacia todo el proyecto para complementar la energía recibida de manera convencional. Asimismo, se aprovecha la gran masa térmica que la tierra provee, adosando al cerro la parte de la edificación donde se encuentran las habitaciones.

El reto de las energías renovables está en satisfacer una gran cantidad de demanda. Las tecnologías existentes son efectivas pero aún no se ha apostado por ellas a gran escala. Lo que nuestras ciudades necesitan para poder alimentarse de manera eficiente de energía renovable implica una intervención de gran envergadura. Al no ser suficiente la adecuación de una vivienda para enfrentar el problema y al necesitar espacios demasiado amplios, con relación al tamaño de la ciudad, no es fácil insertar las urbes en el sistema de la energía renovable. Sin embargo, es desde el urbanismo y el espacio público desde donde empieza a aparecer la propuesta para afrontar el problema en el ámbito de la arquitectura.

\section{OFERTA ACTUAL DE MATERIALES ECOEFICIENTES}

Los avances en la tecnología de la construcción y en la concientización de la necesidad de cambiar nuestros hábitos han desarrollado materiales más adecuados a la realidad en que vivimos, entre los que mencionamos los siguientes:

- Bioblock.- Producido a base de arcilla natural, está diseñado para trabajar a compresión. Se le suele rellenar con corcho granulado para elevar su coeficiente de aislamiento. 
- Arliblock.- Es un bloque de hormigón ligero fabricado con arlita (arcilla expandida granulada muy ligera con alto poder de aislamiento). De base ciega, no usa mortero y por lo tanto evita puentes térmicos.

- Steko bloque.- Modulos de madera (extraída de bosques cultivados de manera sostenible), diseñados para encajar unos con otros, en sentido vertical y horizontal. Se puede rellenar con celulosa. Además de funcionar como cerramiento también soporta carga estructural.

- Cannabric.- Bloque macizo de tierra estabilizada con cal y cañamiza. Está formado por fibras vegetales de cáñamo industrial, cal hidráulica natural y una mezcla de minerales. Además de funcionar como muro de carga, también tiene propiedades contraincendios y de aislamiento térmico y acústico.

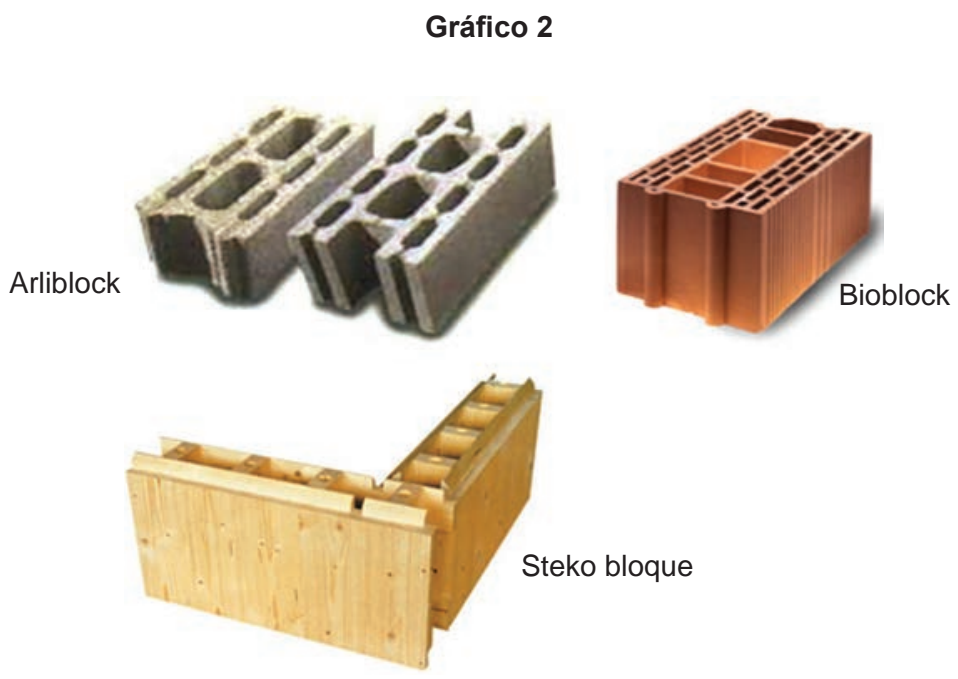

Algunos materiales ecoeficientes que funcionan como módulo para tabiquería.

Fuente: <ecohabitar.org/articulos/art_bioconstruccion/ cerra_verticales.html>.

Estos elementos modulares son ejemplos de lo que en el mundo se está desarrollando para construir de manera sostenible. Sin embargo, ya que ninguno de ellos se produce en el Perú, no es lógico pensar en su uso en nuestro país.

Lo que sí podemos rescatar es la idea del módulo. Los sistemas mencionados intentan resolver el problema constructivo a partir de un solo módulo, que sea adecuado para el clima donde se diseña y que utilice 
materiales locales. Además de ello, es trabajo del arquitecto resolver la forma como utilizar el material del modo más eficiente posible, diseñando los encuentros de dicho módulo de manera horizontal, vertical y en esquinas.

En el proyecto El Refugio se propone, por ello, un módulo de gaviones. Estructurado, a diferencia del gavión utilizado en las riberas de los ríos, con perfiles de acero, que forman una exoestructura que contendrá las piedras de canto rodado para propiciar la inercia térmica del espacio. Al prescindir del mortero, este módulo podrá ser totalmente reutilizado (gráfico 3).

\section{Gráfico 3}

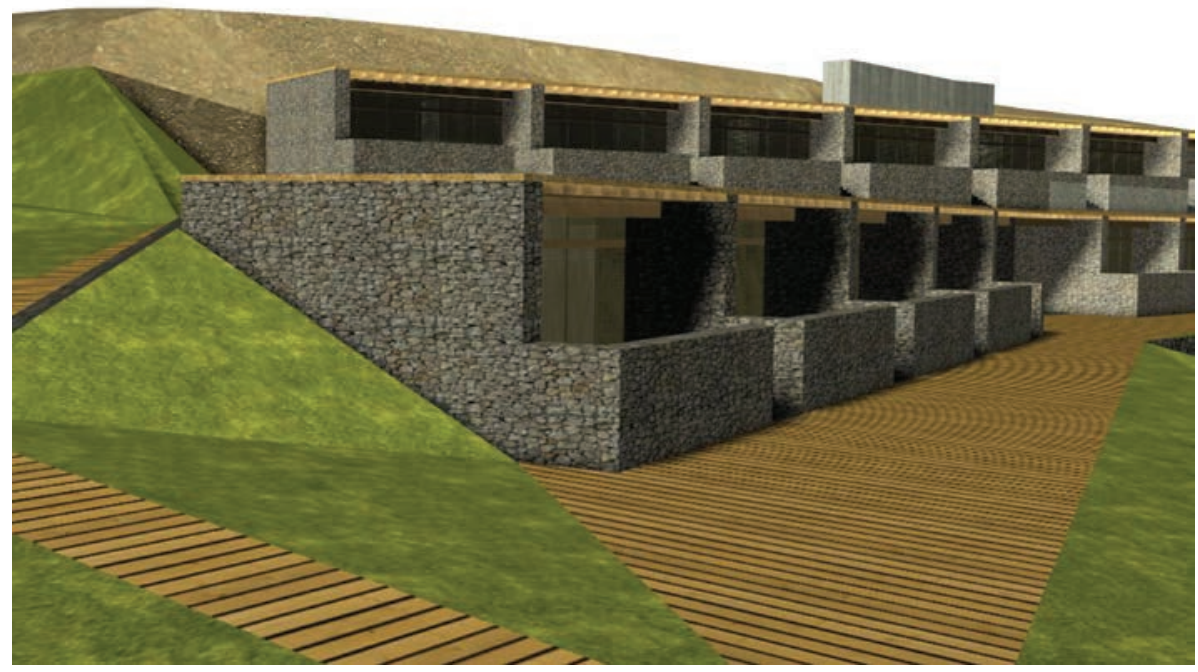

Muros portantes de canto rodado en las habitaciones.

Elaboración propia.

Se han desarrollado, además, alternativas ecoeficientes a los materiales usados convencionalmente en la construcción:

- Biohormigón.- La gravedad del uso de concreto armado tradicional es el alto grado de contaminación que implica la producción del cemento. Por lo tanto, el uso de otros morteros alternativos, como el yeso o la cal (impermeable al agua y al aire pero permeable al vapor de agua), hace del hormigón un sistema estructural elegible si de arquitectura sostenible se habla. Además, se deben evitar las graveras radioacti- 
vas y el uso de aceros pretensados. Sin embargo, siempre es considerado un factor en contra el hecho de que la masa creada no podrá ser reciclada, pero sí podría ser reutilizada como relleno.

- Acero.- El acero es totalmente reciclable si no se encuentra dentro del concreto armado. Crear estructuras de acero (de preferencia entornilladas) es una opción muy eficiente, ya que estas son cien por ciento reciclables, además el acero nos brinda mayor plasticidad en cuanto al diseño (foto 6 y gráfico 4).

Foto 6

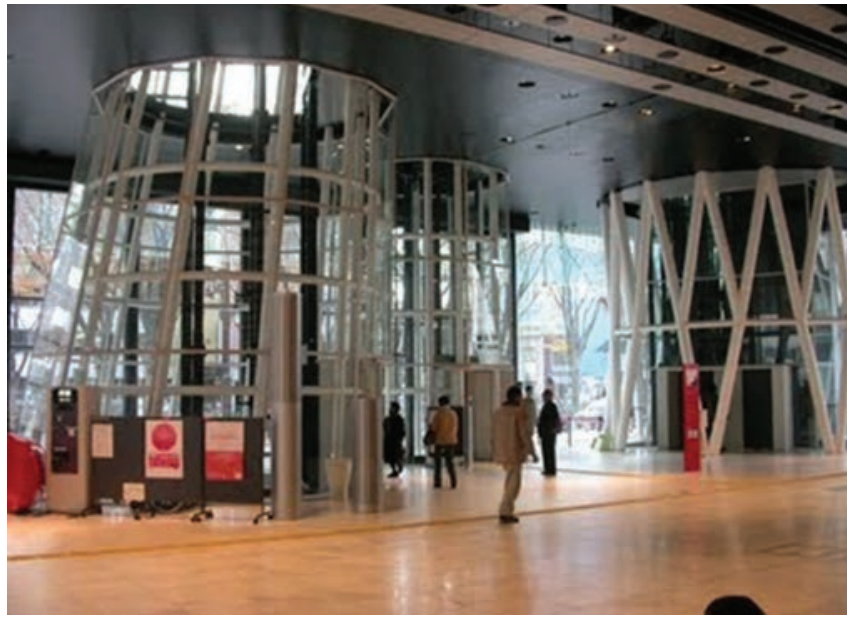

Estructura en acero. Mediateca de Sendai, de Toyo Ito.

Gráfico 4

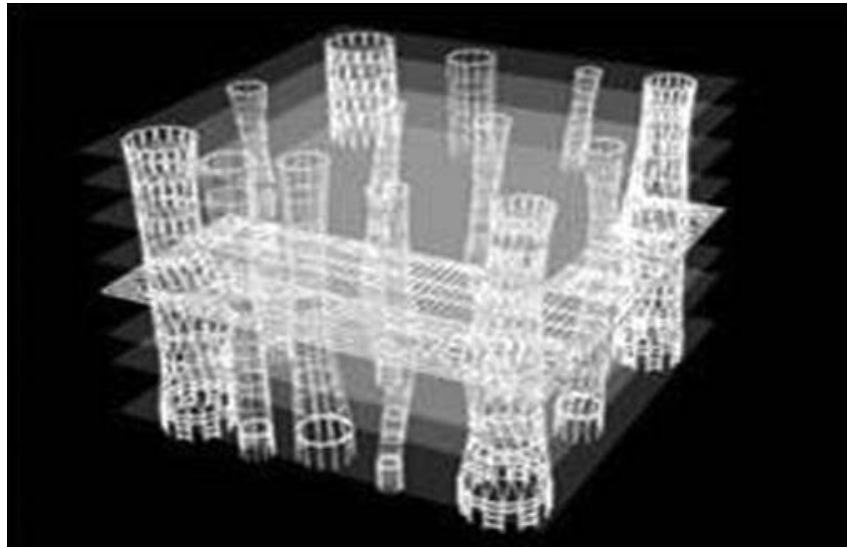

Fuente: <esatcomp1garciajavier.blogspot.com/2009_11_01_ archive.html>. 
- Bambú.- El bambú es una opción estructural muy estudiada y utilizada en el último tiempo. Este acero natural tiene muchos beneficios para los ecosistemas donde es cultivado.

- Maderas alternativas.- La madera proveniente de la práctica responsable de la forestería - actividad sostenible basada en una planificación cuidadosa y un aprovechamiento selectivo - es una opción para vigas, columnas, recubrimiento de pisos, paredes y techos (gráfico 5).

\section{Gráfico 5}

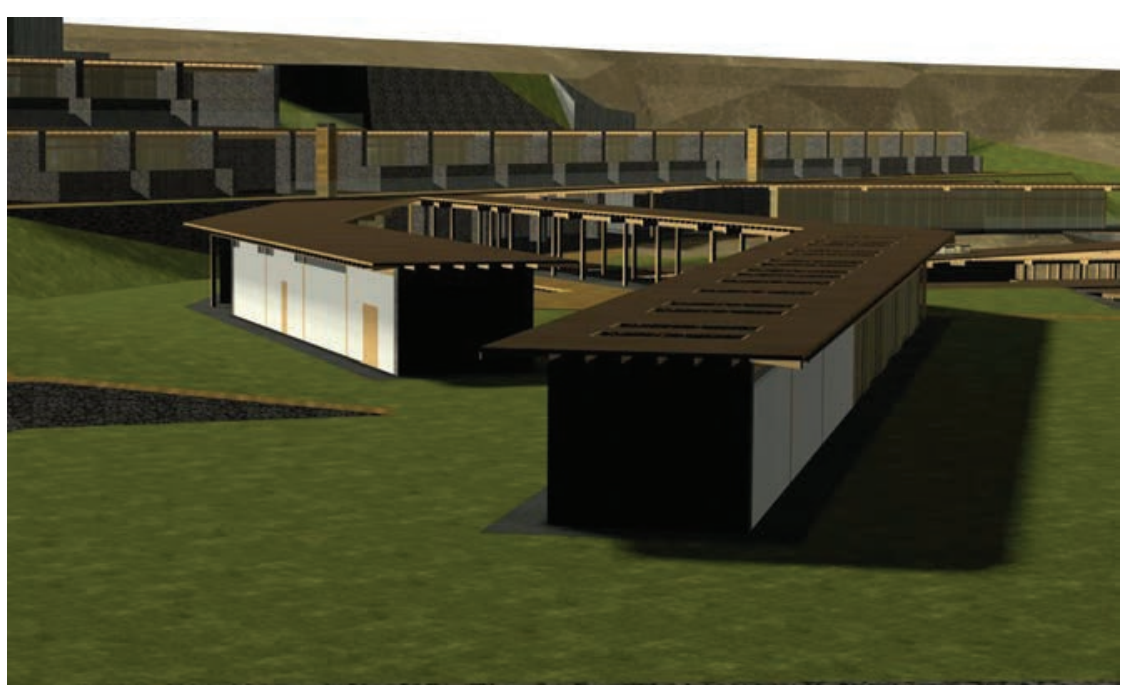

Área del albergue: comedor, talleres y servicios.

Elaboración propia.

Además de los muros portantes hechos de gaviones, para la estructura general del proyecto se utilizan columnas de madera y vigas de madera laminada, hechas con maderas alternativas.

Por ser Chaclacayo un lugar con un clima tan benigno, lo que se debe procurar es la versatilidad de los espacios, de tal manera que sea el usuario quien decida el microclima de su preferencia.

El cerramiento de las habitaciones es versátil. La combinación de la capa interior de mamparas de vidrio corredizas y la piel de paneles con celosías plegables hacen que las habitaciones se puedan conformar a gusto del huésped. 
Los comedores están también cerrados con estas dos capas de vidrio y celosías. Por ser un solo espacio alargado, el comedor de los niños es soportado por columnas de madera; cabe señalar que las especies de madera del proyecto provienen de tala sostenible. En el caso del comedor de huéspedes hay dos bloques, uno adosado al cerro soportado por los muros de gaviones y otro soportado por columnas de madera; entre estos dos volúmenes, una terraza bajo un sol y sombra de madera. Los salones para talleres están divididos (y soportados) por muros de gaviones. Los cerramientos son de vidrio y celosías para actividades como manualidades, arte e idiomas; y con una tabiquería de paneles GYPLAC (plancha de celulosa de papel reciclado) estructuradas en madera, con fibra de lana como aislante acústico, en el caso de los salones de música y canto.

El área del espacio de distracción es una mezcla de muros de gavión (en las partes que deben contener parte del terreno que están rodeando), y a medida que los volúmenes se desprenden la estructura se hace de columnas de madera, sin ningún cerramiento para poder disfrutar del exterior y del paisaje (gráfico 6).

\section{Gráfico 6}

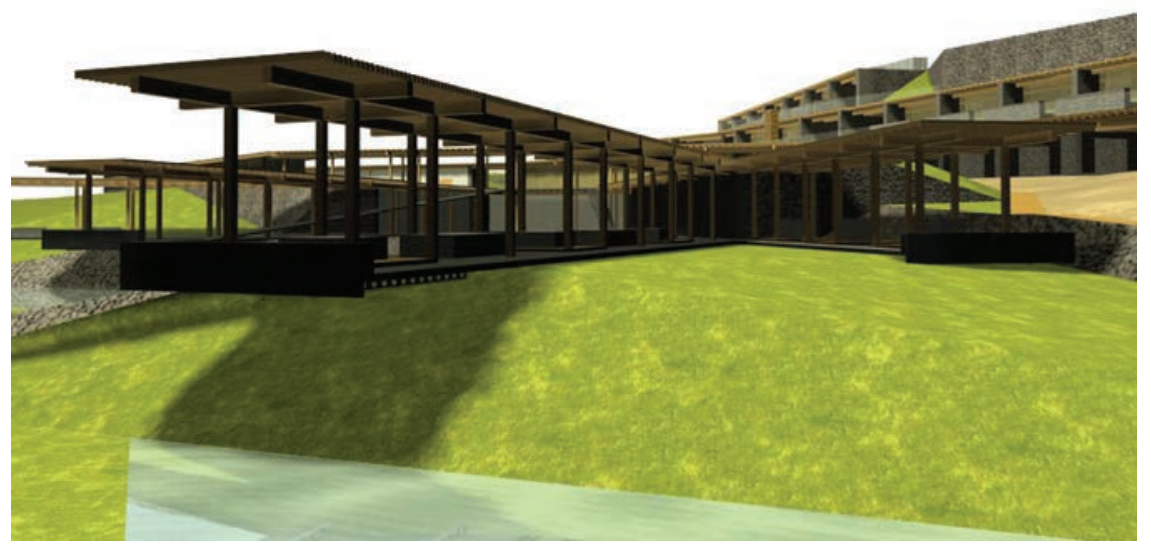

Volado con terrazas en el espacio de distracción.

Elaboración propia. 


\section{TRATAMIENTO DE RESIDUOS}

El proyecto de arquitectura ecoeficiente debe intentar ser parte de los ciclos naturales e imitar los ciclos ecológicos mediante los cuales los recursos y residuos se equilibran y armonizan. El objetivo principal será reutilizar y reciclar la mayor cantidad de residuos posibles. La materia inorgánica se selecciona para ser reciclada, la materia orgánica se trata para obtener de ella nuevas materias primas. La tecnología existe, solo se trata de hacerla parte de los nuevos espacios que se diseñan.

\section{Gráfico 7}

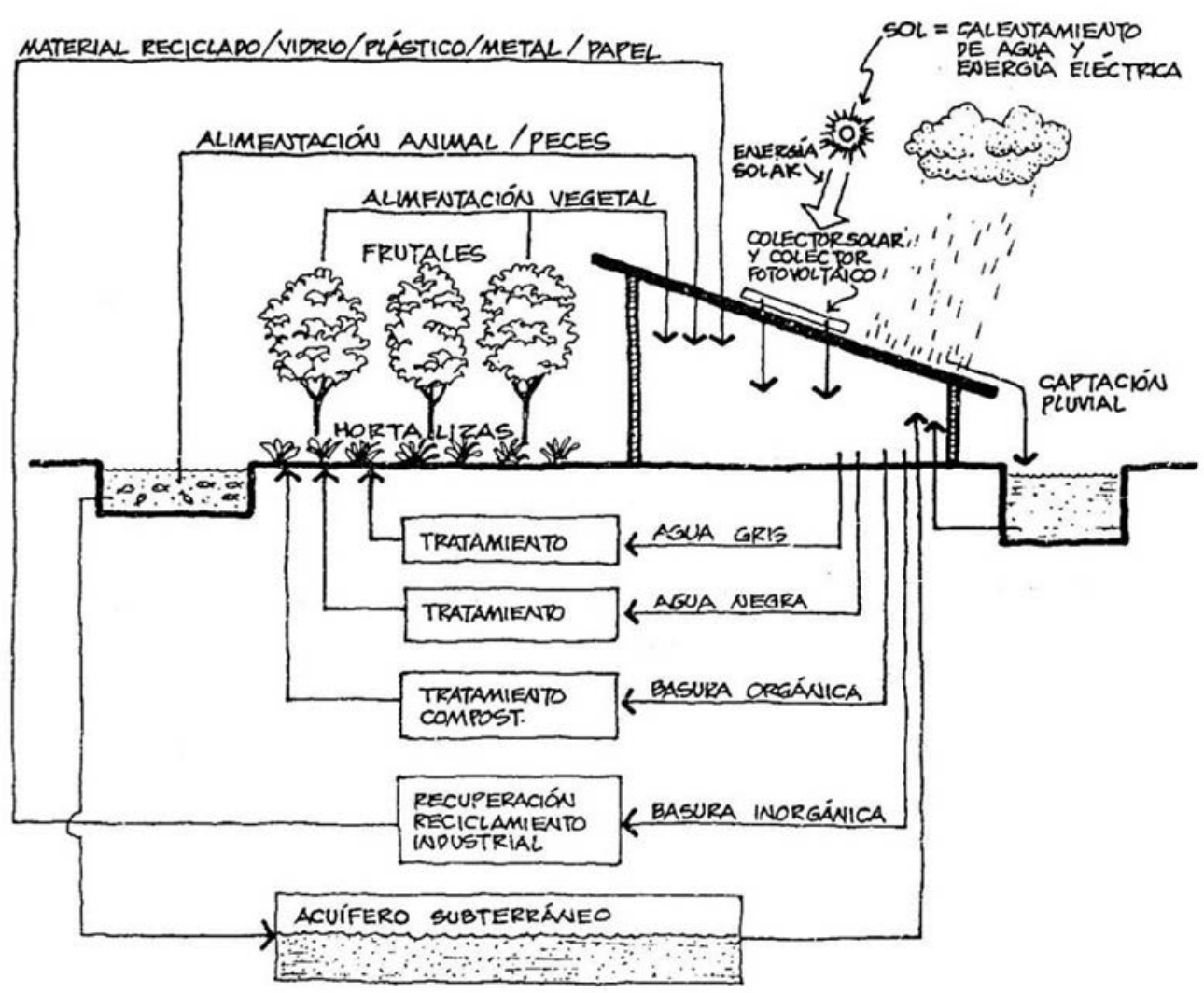

Casa ecológica que cierra sus ciclos para buscar la ecoeficiencia.

Fuente: Deffis Caso (1994) 


\subsection{Materia orgánica: Tratamiento de aguas y compost}

Las aguas grises son las resultantes de las redes potables de primer uso: duchas, lavamanos y, en algunos casos, lavaderos de cocina; la condición es que no se utilice detergente, para lo cual ya existen productos alternativos de limpieza, y que se coloque una trampa de grasas. Los aparatos sanitarios se conectan a un drenaje independiente, separado de las aguas negras, para ser tratadas y reutilizadas. Si hay presencia de lluvias, el drenaje de estas también puede conectarse a esta red.

Los tratamientos dependen del uso final que se les vaya a dar a las aguas grises. Estas se pueden purificar mediante un proceso de decantación, filtración, clarificación y desinfección; para luego ser bombeadas a un tanque y utilizadas en inodoros o en el riego de las áreas verdes.

\section{Foto 7}

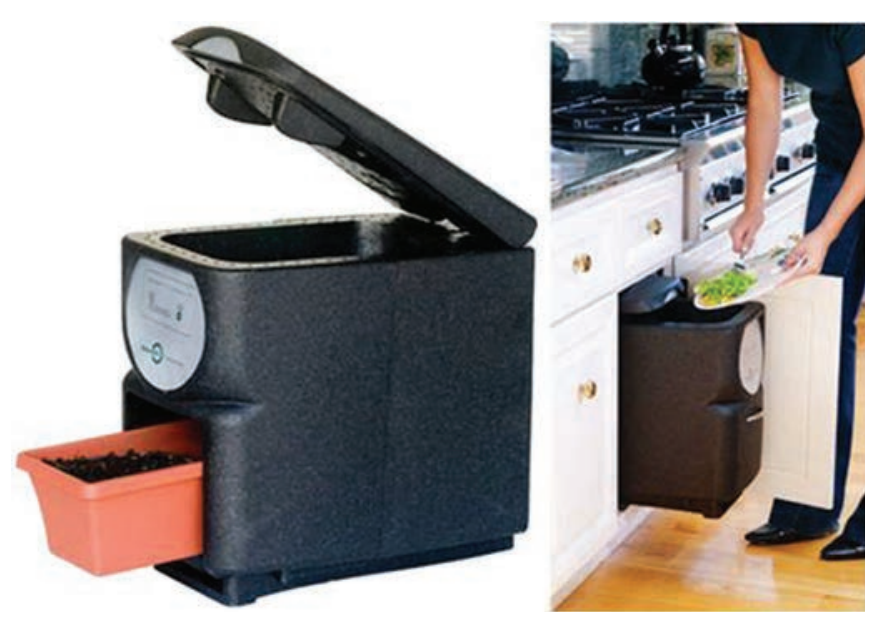

Tacho para separar los residuos orgánicos que irán a la compostadora. Pensar en la estética del producto ecoeficiente en el momento del diseño contribuye al aumento de su popularidad.

Fuente: <http://www.infojardin.com/foro/showthread.php? $\mathrm{t}=129059$ \&page $=5>$. 
Otro proceso de tratado de estas aguas es el filtro jardinera. Este incorpora al proceso el uso de la tierra y cierto tipo de vegetación para ayudar a filtrar las aguas. Además, esta técnica nutre la tierra con el fósforo, el potasio y el nitrógeno contenidos en las aguas grises.

La reutilización de aguas grises puede llegar a ahorrar un 30 a 40\% del agua potable. Pero el costo de instalación de un sistema de reutilización de aguas grises para una familia promedio llega todavía a los 1.100 euros.

Las aguas negras proceden de los inodoros, incluyen los residuos sólidos y líquidos. Si bien en el proyecto se plantea enviarlas a la planta de tratamiento de aguas negras de Carapongo, no está de más señalar algunos sistemas de tratamiento. Uno de estos sistemas es el denominado 'planta paquete de aereación prolongada'. Sigue el siguiente proceso: separación de sólidos, digestión aeróbica y sedimentación, para luego repetir el proceso con el sedimento. Existe también la posibilidad de utilizar silos sostenibles, muy usados en zonas rurales, los silos han evolucionado en su diseño. En algunos proyectos se plantea la posibilidad de que los residuos orgánicos almacenados en estos silos sean compostados. En otros casos hasta se alejan los silos de la casa o proyecto para evitar malos olores y facilitar su desalojo.

El compost es un fertilizante obtenido de la descomposición de los residuos orgánicos, que, de esta manera, podrían contribuir a mejorar la producción de nuestros alimentos. Este abono natural no quema las plantas, como sucede en ocasiones con el abono químico. Contiene nitrógeno, fósforo y potasio, micronutrientes que refuerzan las plantas. Contiene también minerales como zinc, cobre, magnesio y selenio, indispensables en pequeñas cantidades para la fertilidad de la tierra y la salud del hombre. Otra ventaja del compost es que contribuye a facilitar la labranza, impidiendo la formación de charcos, ya que la materia orgánica absorbe rápidamente el agua.

Un modo rústico de producir el compost es cavando un hoyo en el suelo o haciendo un montículo con la materia orgánica y luego cubrirlo. Sin embargo, se están extendiendo cada vez más en el mercado opciones más citadinas; desde el cilindro para compost, que no dista mucho de ser un basurero grande, que puede girar sobre el eje horizontal para lograr la descomposición aeróbica necesaria, hasta pequeños basureros que pueden incluirse en el mobiliario de las cocinas. 


\subsection{Residuos inorgánicos}

La única solución que la humanidad ha dado hasta el momento al problema de la basura es quitársela de la vista, arrojándola fuera de las ciudades o centros poblados y en algunos casos enterrarla.

\section{Foto 8}

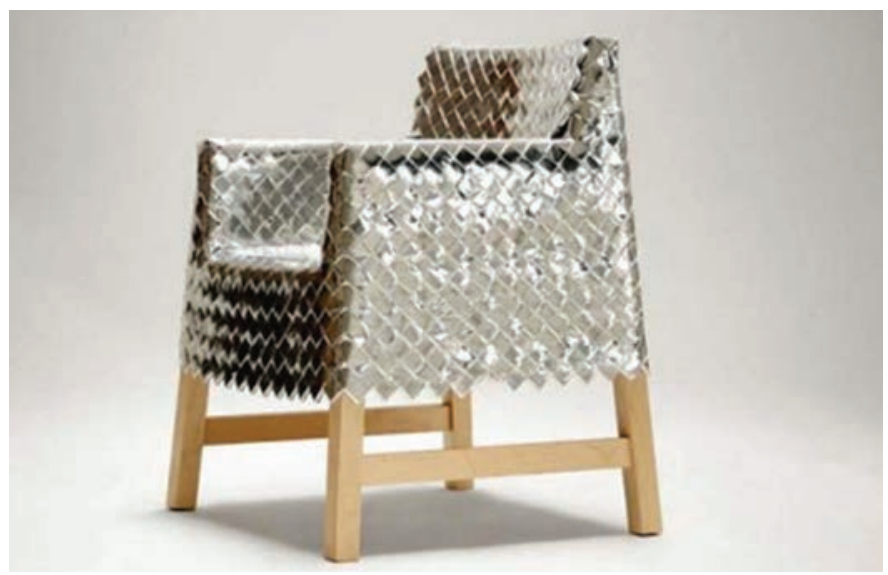

Por muy estéticas y vanguardistas que sean las propuestas, el problema de la basura sigue siendo que producimos más basura de la que nuestros ecosistemas pueden absorber.

Fuente: <inhabitat.com/emilano-godoys-shiny-snowjob-chair -is-made-from-recycled-candy-wrappers/>.

Debido a que la población mundial está en aumento considerable, los desechos de nuestras sociedades se han convertido en un problema cada vez mayor. No solo por la dificultad y alto costo que implica arrojar los residuos en tiraderos o enterrarlos, sino porque la naturaleza no puede seguir absorbiéndolos. Al respecto, Deffis Caso dice: "Los desechos sólidos constituyen una expresión física, manifiesta y evidente de esta faceta destructiva de la sociedad" (1994: 274).

Una opción para la reducción de la basura es la pirólisis o destilación destructiva. Este proceso consiste en la descomposición de un material por calentamiento en ausencia de aire. Pero no es cien por ciento eficiente, ya que requiere de una clasificación previa y esta acción ya estaría convirtiendo la basura en productos aptos para el reciclaje o la reutilización. 
La reutilización o recuperación industrial comprende una variedad muy grande de procesos. El objetivo es hacer recircular los materiales de desecho, reconducirlos a los procesos de manufactura. Se separan el vidrio, el plástico la película, el plástico rígido, el papel, el cartón y el metal. Los desechos orgánicos en este proceso se podrían utilizar para elaborar galletas proteicas para animales o compost. Luego estos elementos además podrían ser reciclados, los que en la mayoría de las veces resultan compuestos inferiores a los originales, por lo que no se pueden utilizar para producir la misma calidad de productos.

La única forma de desaparecer los residuos sólidos o la basura es no produciéndolos. Es decir, procurar cerrar los círculos del sistema, y eso implica repensar todos nuestros procesos de diseño. Gran parte de los productos que la industria nos ofrece está pensada para utilizarse una sola vez o está elaborada con materiales híbridos que ya no se pueden separar, sin contar con el hecho de que la mayoría contiene algún químico tóxico que no debería estar ahí.

En lo que se refiere al agua, se contará con tres lagunas para el tratamiento de las aguas grises. En las dos primeras lagunas se dará el filtrado (con especies vegetales especializadas en "alimentarse" del nitrógeno y fósforo que contienen las aguas grises en la segunda de ellas). La tercera y última laguna será utilizada para piscicultura, actividad cuyo producto servirá para el alimento de los huéspedes y de los niños del albergue.

Las aguas negras se enviarán a la planta de tratamiento de aguas residuales de Carapongo, en Huaycán, que es a donde se dirige todo el sistema de desagüe de Chaclacayo.

De los residuos orgánicos se producirá compost, el cual será vendido y utilizado en el huerto, donde los niños aprenderán a cultivar alimentos que también servirán para proveer las despensas de las cocinas. Los residuos inorgánicos se clasificarán para ser reciclados en las plantas de tratamiento respectivas. Además, en los talleres para niños se incluirá este tipo de materiales para las manualidades que podrán ser vendidas a los visitantes.

\section{TOPOGRAFÍA Y CARÁCTER ESPACIAL}

El paisaje y la topografía del terreno son propicios para generar diferentes situaciones espaciales, permitiendo una lógica de emplazamien- 
to que además de ser eficiente, se amarra con la intención espacial y la búsqueda diferenciada de visuales en todo el proyecto.

La parte superior, adosada al cerro, albergará volúmenes semienterrados que funcionarán como habitaciones, con el fin de conseguir la mayor cantidad de inercia térmica para el confort térmico de los espacios de alojamiento y albergue. Esta ubicación pretende enfrentar cada habitación con una vista panorámica del terreno y del paisaje urbano, además de desplegar el proyecto a lo largo del terreno, para refrescarlo en verano y exponerlo a la radiación en invierno.

Las partes planas del terreno recibirán los volúmenes del área social, que se posarán sobre este, permitiendo la generación de vacíos entre ellos. Esta acción hace que el proyecto se vea a sí mismo dentro del paisaje.

En la sección más baja del terreno, donde los desniveles son un poco más pronunciados, los volúmenes brotarán del interior de la tierra para luego despegarse del suelo y mirar hacia la parte con mayor vegetación. En este sector se colocará la programación relacionada con la distracción (gráfico 7).

\section{Gráfico 7}

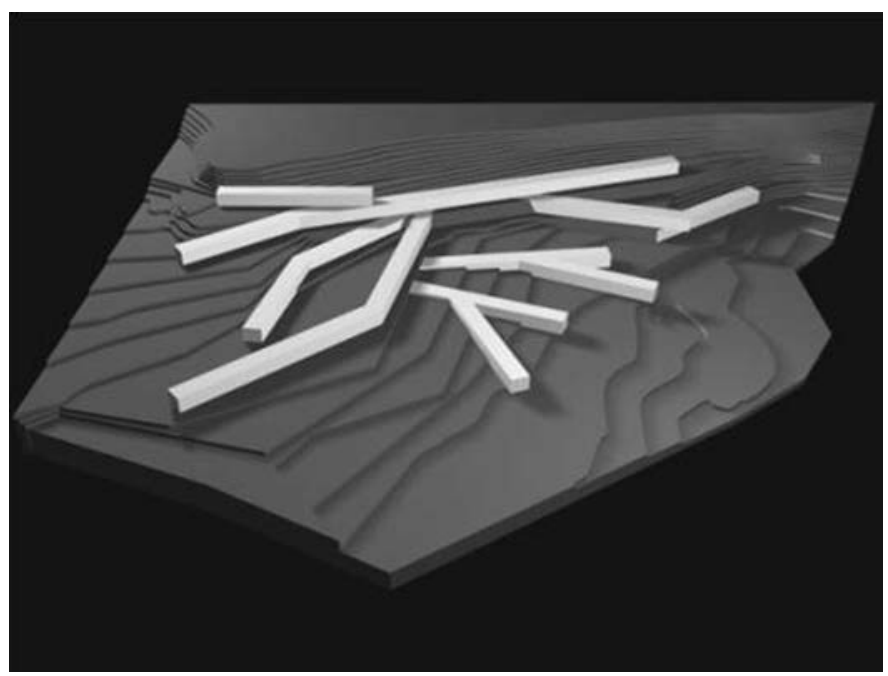

Emplazamiento del proyecto. Cómo los volúmenes se encuentran con el terreno.

Elaboración propia. 
La selección del uso de sistemas de control medioambiental se basa en las siguientes premisas:

- Captación de la radiación solar utilizando piedra, de gran inercia térmica, además de la opción que por efecto invernadero generan las vidrieras corredizas.

- Protección de la radiación mediante celosías plegables y aleros de 1,20 metros en todos los bordes del proyecto (gráfico 8).

Gráfico 8

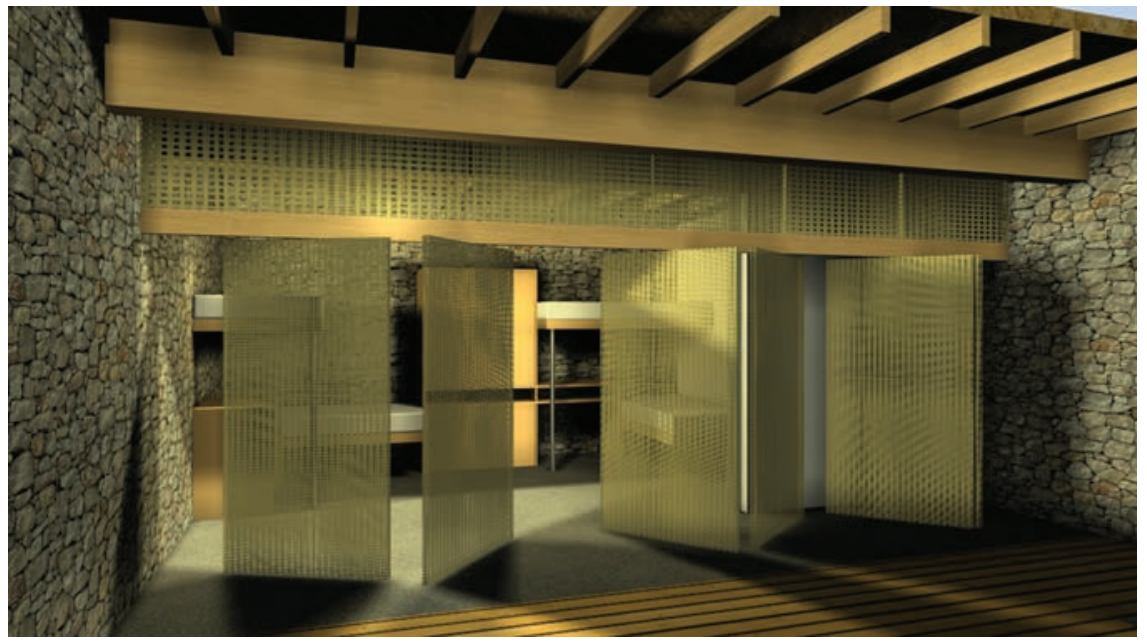

Versatilidad de las celosías en las habitaciones. Elaboración propia.

- Ventilación natural cruzada en todos los ambientes sociales. Las habitaciones tienen la posibilidad de abrirse totalmente al exterior, convirtiéndose en una terraza. Las cocinas se ventilan mediante aspiradores.

- Iluminación natural, que incluye el uso de las claraboyas y los lucernarios de la Lima antigua.

La arquitectura es una disciplina que afronta diferentes variables, y el arquitecto debe poder equilibrar todas estas variables para conseguir el mejor resultado posible. Por ello se decide, cuando el espacio lo requiere, utilizar incluso concreto armado y acero, para lograr sensaciones espaciales que son irrenunciables desde el punto de vista proyectual. 
La ecoeficiencia es un concepto en el que se puede apoyar para desarrollar herramientas que contribuyan a la creación de una arquitectura amigable con el medio ambiente; no debe ser nunca un conjunto de reglas cuadriculadas, que frenen el potencial de la arquitectura, en lugar de contribuir a la espacialidad.

Si bien la premisa de este proyecto es lograr una arquitectura ecoeficiente, es el espacio el personaje principal. El espacio como generador de emociones, como refugio de la vida y como objeto de estudio de la arquitectura (gráfico 9).

\section{Gráfico 9}

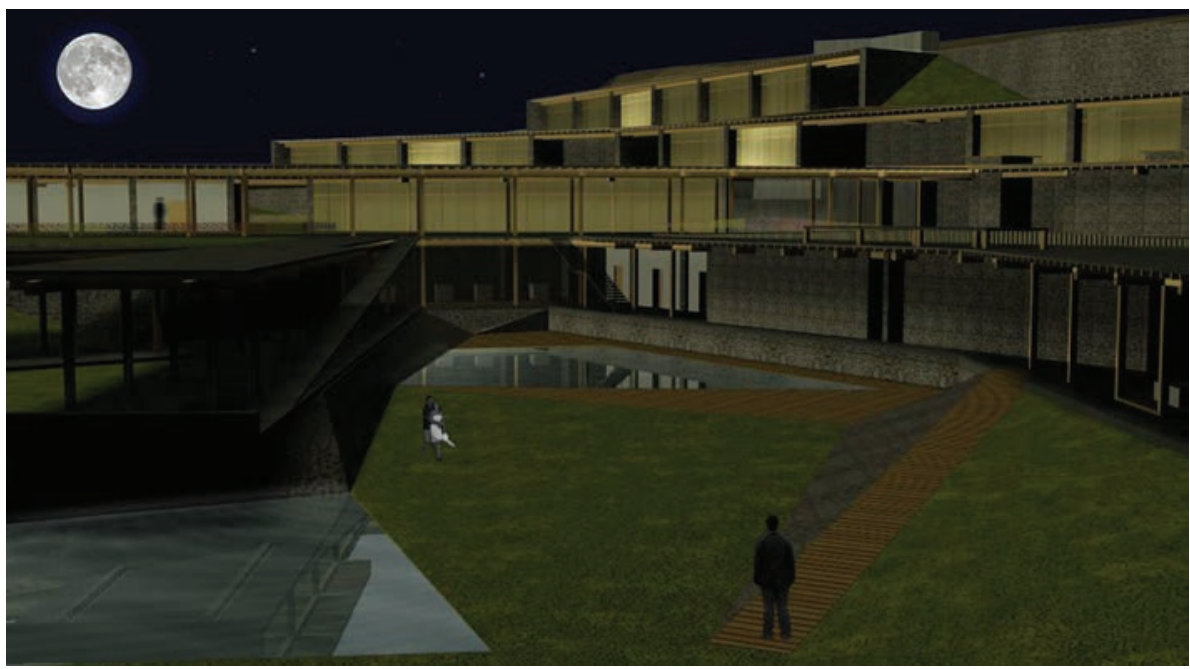

Vista nocturna del proyecto. Vacío generado por los volúmenes para estar alrededor de la piscina.

Elaboración propia.

Cuando el espacio se encuentra con la vida es cuando estamos haciendo arquitectura. En un proyecto ecoeficiente el valorar la vida se intensifica. Los huéspedes descansarán en un entorno que promueve el respeto por el medio ambiente y predica lo eficiente que resulta la imitación de la naturaleza. Los niños se alimentarán con productos cultivados con abonos naturales y aprenderán que todo residuo puede servir para algo y que no tiene sentido producir cosas que no se puedan reutilizar o reciclar. 
Insertar un proyecto de arquitectura ecoeficiente es un testimonio y un ejemplo de cómo será nuestra vida cuando tomemos real conciencia de la responsabilidad que tenemos, no solo como arquitectos, sino como habitantes de este planeta.

\section{BIBLIOGRAFÍA}

Arenas Delgado, Antonio (1975). Chaclacayo. Reseña y reportaje. Lima: Talleres Gráficos Cecil S.A.

Agurto, Santiago (1987). Estudios acerca de la construcción, arquitectura y planeamiento incas. Lima: Capeco.

Wikipedia (30 de junio del 2005). Chaclacayo. <http://www.wikipedia. org/wiki/Archivo:Club_Terrazas_Chaclacayo.jpg>. [Consulta: 5 de marzo del 2011.]

Basilisco (junio del 2006). Compostera. Infojardín [foro]. Valencia. $<$ http:// www.infojardin.com/foro/showthread.php?t=129059\&page $=5>$. [Consulta: 16 de febrero del 2011.]

Colegio de Arquitectos del Perú (2009). XIII Bienal Nacional de Arquitectura del Perú. Lima: Ars Asesoría y Servicio.

Darnil, Sylvain y Mathieu Le Roux (2006). Cambiar el mundo. 3. ${ }^{a}$ edición. Madrid: Santillana Ediciones Generales.

Deffis Caso, Armando (1994). La casa ecológica autosuficiente. México D. F.: Árbol Editorial S.A.

Edwards, Brian (2008). Guía básica de la sostenibilidad. Barcelona: Gustavo Gili.

García Fernández Carrión, Javier (18 de noviembre del 2009). "Si se piensa en los vacíos en lugar de trabajar con los elementos sólidos la verdad aparece". Javier García Fdez Carrión [blog]. <http:// www.esatcomp1garciajavier.blogspot.com/2009_11_01_archive. html>. [Consulta: 16 de febrero del 2011.]

Hawthorne, Christopher y Alanna Stang (2005). The green house. New directions in sustainable architecture. China: Princeton Architectural Press.

Fehrenbacher, Jill (6 de febrero del 2011). “En Pieza’s Shimmering Volivik Chandelier is made from recycled Bic pens". Inhabitat [blog]. 
Nueva York. <http://www.inhabitat.com/en-piezas-shimmeringvolivik-chandelier-made-from-used-bic-pens/>. [Consulta: 16 de febrero del 2011.]

Instituto Cerdá, IDAE (1999). Guía de la edificación sostenible. Calidad energética y medioambiental en edificación. Madrid: Centro de Publicaciones IDAE.

Marin, Toni et al. (2005). Cerramientos verticales en bioconstrucción. Ecohabitar. <http://www.ecohabitar.org/articulos/art_bioconstruccion/cerra_verticales.html>. [Consulta: 16 de febrero del 2011.]

Perec, Georges (2004). Especies de espacios. Barcelona: Imprime Novagrafik S.A.

----. (2002). El lugar de la arquitectura. Santiago de Chile: Ediciones ARQ.

Pham, Diane (4 de febrero del 2011). "Emilano Godoy's shiny snowjob chair is made from recycled Candy Wrappers". Inhabitat [blog]. Nueva York. <http://www.inhabitat.com/emilano-godoys-shinysnowjob-chair-is-made-from-recycled-candy-wrappers/>. [Consulta: 16 de febrero del 2011.]

Singh, Timon. "Netherlands to roll out energy-generating sola road bike path". Inhabitat [blog]. Bristol. <http://www.inhabitat.com/ netherlands-to-roll-out-energy-generating-solaroad-bike-path/>. [Consulta: 20 de enero del 2011.]

Vitalis. Ecoeficiencia en el sector de la Construcción. <www.vitalis.net/ ecoeficiencia.htm>. [Consulta: 15 de marzo de 2008.]

Zimmer, Lori. "Wind turbine bridge transforms italian viaduct into public space". Inhabitat [blog]. Nueva York. <http://www.inhabitat. com/solar-wind-turbine-bridge-repurposes-viaduct-for-public-space/>. [Consulta: 20 de enero del 2011.] 